\title{
Yeast Methylotrophy: Metabolism, Gene Regulation and Peroxisome Homeostasis
}

\author{
Hiroya Yurimoto, ${ }^{1}$ Masahide Oku, ${ }^{1}$ and Yasuyoshi Sakai ${ }^{1,2}$ \\ ${ }^{1}$ Division of Applied Life Sciences, Graduate School of Agriculture, Kyoto University, Kitashirakawa-Oiwake, Sakyo-ku, \\ Kyoto 606-8502, Japan \\ ${ }^{2}$ CREST, Japan Science and Technology Agency, 5 Sanbancho, Chiyoda-ku, Tokyo 102-0075, Japan
}

Correspondence should be addressed to Yasuyoshi Sakai, ysakai@kais.kyoto-u.ac.jp

Received 12 April 2011; Accepted 9 May 2011

Academic Editor: Jeremy D. Semrau

Copyright ( $) 2011$ Hiroya Yurimoto et al. This is an open access article distributed under the Creative Commons Attribution License, which permits unrestricted use, distribution, and reproduction in any medium, provided the original work is properly cited.

\begin{abstract}
Eukaryotic methylotrophs, which are able to obtain all the carbon and energy needed for growth from methanol, are restricted to a limited number of yeast species. When these yeasts are grown on methanol as the sole carbon and energy source, the enzymes involved in methanol metabolism are strongly induced, and the membrane-bound organelles, peroxisomes, which contain key enzymes of methanol metabolism, proliferate massively. These features have made methylotrophic yeasts attractive hosts for the production of heterologous proteins and useful model organisms for the study of peroxisome biogenesis and degradation. In this paper, we describe recent insights into the molecular basis of yeast methylotrophy.
\end{abstract}

\section{Introduction}

Reduced $\mathrm{C}_{1}$-compounds, such as methane and methanol, are relatively abundant in nature. Methylotrophs, that have the ability to utilize $\mathrm{C}_{1}$-compounds as the sole source of carbon and energy, also appear to be ubiquitous in nature. A diverse range of prokaryotes and eukaryotes can utilize $C_{1}$ compounds for growth, and methylotrophs have a diverse range of metabolic pathways for assimilating and dissimilating $\mathrm{C}_{1}$-compounds [1-4]. Prokaryotic methylotrophs can utilize a variety of $\mathrm{C}_{1}$-compounds (e.g., methane, methanol, methylamine), while eukaryotic methylotrophs can only use methanol as a carbon source, and methylamine not as a carbon source but as a nitrogen source. The latter group of organisms is limited to a number of yeast genera including Candida, Pichia, and some genera that were recently separated from Pichia, that is, Ogataea, Kuraishia, and Komagataella [5].

Since the first isolation in 1969 [6], methylotrophic yeasts have been studied intensively in terms of both physiological activities and potential applications. In the early 1970s, production of single cell protein (SCP) using methanol as a carbon source was studied intensively [7, 8]. These studies established a high-cell-density cultivation method although large-scale production of SCP from methanol was eventually found not to be economically feasible. The metabolic pathways involved in methanol assimilation and dissimilation and characterization of the enzymes have been described in Hansenula polymorpha (Pichia angusta) and Candida boidinii [9-12]. One major finding was the strong inducibility of these enzymes by methanol. A variety of genes encoding enzymes and proteins involved in methanol metabolism have since been cloned, and the regulation of methanol-inducible gene expression has been studied [13, 14]. Methylotrophic yeasts also have been used as model organisms for peroxisome biogenesis and degradation, because methylotrophic growth in yeasts is accompanied by the massive proliferation of peroxisomes, membrane-bound organelles that contain several methanolmetabolizing enzymes [15-17].

Heterologous gene expression systems driven by strong methanol-inducible promoters have been developed in a number of methylotrophic yeast strains, including P. pastoris, H. polymorpha, P. methanolica, and C. boidinii [18-22]. 


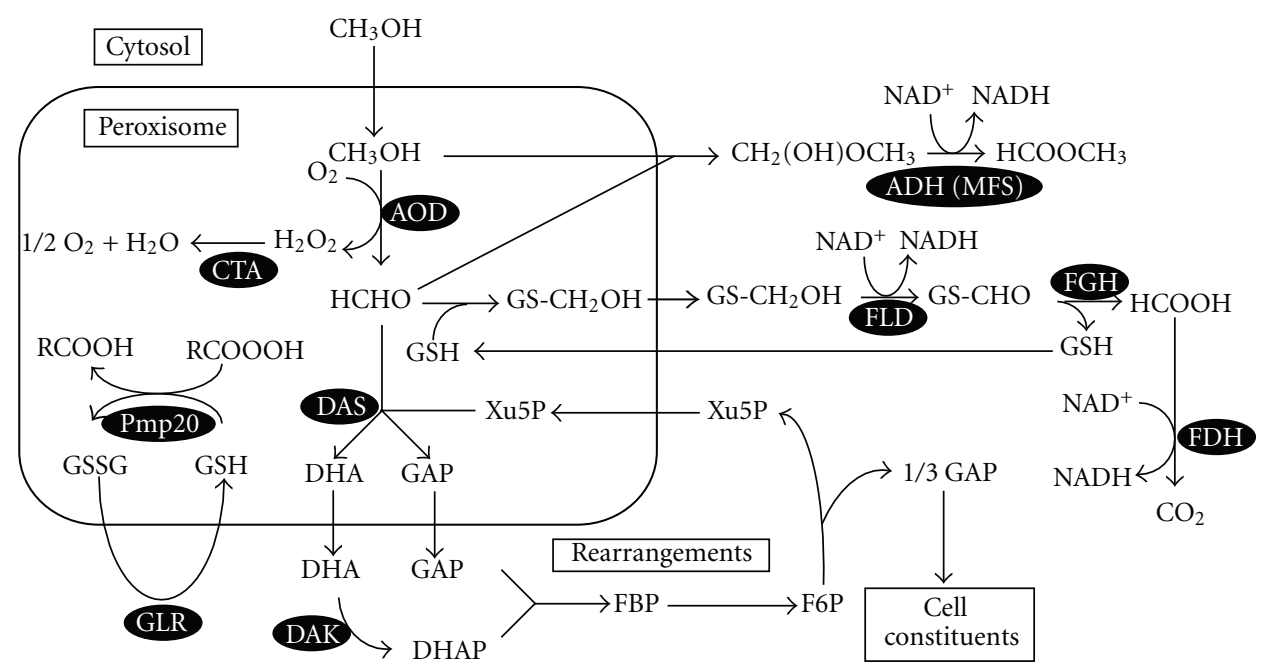

FIGURE 1: Outline of methanol metabolism in methylotrophic yeasts. Enzymes: ADH (MFS): alcohol dehydrogenase (methylformatesynthesizing enzyme); AOD: alcohol oxidase; CTA: catalase; DAK: dihydroxyacetone kinase; DAS: dihydroxyacetone synthase; FDH: formate dehydrogenase; FGH: S-formylglutathione hydrolase; FLD: formaldehyde dehydrogenase; GLR: glutathione reductase; Pmp20: peroxisome membrane protein which has glutathione peroxidase activity. Abbreviations: DHA: dihydroxyacetone; DHAP: dihydroxyacetone phosphate;

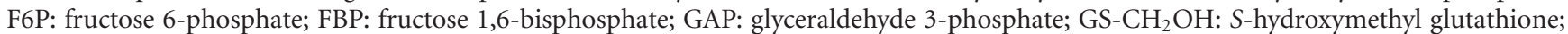
GS-CHO: S-formylglutathione; GSH: reduced form of glutathione; GSSG: oxidized form of glutathione; RCOOOH: alkyl hydroperoxide; Xu5P: xylulose 5-phosphate.

Increasing industrial and academic use of these expression systems has led to the heterologous production of a large number of proteins including enzymes, antibodies, cytokines, plasma proteins, and hormones. Some of the advantages of these systems include (i) cheap synthetic saltbased media for growing the yeast, (ii) strong and tightly regulated promoters induced by methanol and repressed by glucose or ethanol, and (iii) the fact that the processes of protein folding, secretion, and other functions in these yeasts are similar in many respects to the same processes in higher eukaryotes.

Recently, much attention has been paid to methanol as an alternative carbon source to replace coal and petroleum $[23,24]$. Industrially, methanol is prepared from "syngas" $\left(\mathrm{CO}\right.$ and $\mathrm{H}_{2}$ ) or reductive conversion of atmospheric $\mathrm{CO}_{2}$ with $\mathrm{H}_{2}$. Syn-gas can be produced from an abundant natural resource, methane, which is a major component of natural gas and is also obtained from renewable biomass [25]. Because methanol is a cheap and nonfood substrate, it has become a promising feedstock for biotechnological and chemical processes. In natural environments, methanol is produced by oxidation of methane by methane-oxidizing bacteria and also by decomposition of plant pectins and lignins that contain methylester and methoxyl groups, respectively [26, 27]. Methanol is oxidized to $\mathrm{CO}_{2}$ by methylotrophic bacteria and yeasts. Thus, methylotrophs play indispensable roles in the global carbon cycle between methane and $\mathrm{CO}_{2}$ called "the methane cycle." A thorough understanding of the molecular basis of methylotrophy is needed not only to better understand the global methane cycle but also to permit more efficient use of methanol as a renewable carbon source.

\section{Outline of Yeast Methanol Metabolism and the Physiological Roles of Associated Enzymes}

All methylotrophic yeasts use a common methanol-utilizing pathway. An outline of methanol metabolism in methylotrophic yeasts is summarized in Figure 1 [13]. Methanol is first oxidized by alcohol oxidase (AOD) to form formaldehyde and hydrogen peroxide, which are both highly toxic compounds. Formaldehyde is a central intermediate situated at the branch point between assimilation and dissimilation pathways [2]. A portion of formaldehyde is fixed to xylulose 5 -phosphate (Xu5P) by dihydroxyacetone synthase (DAS) forming dihydroxyacetone (DHA) and glyceraldehyde 3phosphate (GAP), which are used for the synthesis of cell constituents and the regeneration of Xu5P. AOD and DAS are located in peroxisomes together with catalase (CTA), which breaks down hydrogen peroxide. DHA and GAP are further assimilated within the cytosol. DHA is phosphorylated by dihydroxyacetone kinase (DHAK), and, subsequently, dihydroxyacetone phosphate (DHAP) and GAP form fructose 1,6-bisphosphate which is then utilized for regeneration of $\mathrm{Xu} 5 \mathrm{P}$ and for biosynthesis of cell constituents.

Another portion of formaldehyde is further oxidized to $\mathrm{CO}_{2}$ by the cytosolic dissimilation pathway. Formaldehyde generated by AOD reacts nonenzymatically with the reduced form of glutathione (GSH) to generate $S$-hydroxymethyl glutathione ( $S$-HMG). $S$-HMG is then oxidized to $\mathrm{CO}_{2}$ through the cytosolic GSH-dependent oxidation pathway, which is ubiquitous in nature [28]. $\mathrm{NAD}^{+}$-linked and GSHdependent formaldehyde dehydrogenase (FLD) uses S-HMG as a substrate to yield $S$-formylglutathione $(S-F G)$ and 
TABle 1: Phenotypes associated with disruptions in genes encoding methanol-metabolizing enzymes in C. boidinii.

\begin{tabular}{lccc}
\hline Enzyme & Gene name & Mutant (M)/disruptant (D) phenotype & Reference \\
\hline Alcohol oxidase & $A O D 1$ & no growth & {$[30]$} \\
Dihydroxyacetone synthase & $D A S 1$ & no growth & {$[31]$} \\
Formaldehyde dehydrogenase & $F L D 1$ & no growth & {$[32]$} \\
S-Formylglutathione hydrolase & $F G H 1$ & weak growth & {$[33]$} \\
Formate dehydrogenase & $F D H 1$ & weak growth & {$[34]$} \\
Alcohol dehydrogenase & $A D H 1$ & weak growth & {$[35]$} \\
Catalase & $C T A 1$ & weak growth & {$[43]$} \\
Pmp20 & PMP20 & no growth & {$[36]$} \\
\hline
\end{tabular}

NADH. S-FG is then hydrolyzed to formate and GSH by $S$ formylglutathione hydrolase (FGH). $\mathrm{NAD}^{+}$-linked formate dehydrogenase $(\mathrm{FDH})$ is the last enzyme involved in the methanol dissimilation pathway and generates $\mathrm{CO}_{2}$ and NADH through the oxidation of formate.

We have studied the physiological role of the methanolmetabolizing enzymes by cloning and disrupting the corresponding genes in C. boidinii [22, 29]. The cloned genes and phenotypes of the associated mutants are summarized in Table 1. Obviously, AOD and DAS are both essential enzymes for methylotrophy in yeast $[30,31]$. However, the enzymes involved in the GSH-dependent formaldehyde oxidation pathway have different roles in methanol metabolism. The FLD1-disrupted strain $(f g h 1 \Delta)$ was unable to grow on methanol under chemostat conditions even with a low dilution rate, indicating that FLD is essential for growth on methanol [32]. The FGH1- and FDH1-disrupted strains ( $g h 1 \Delta$ and $f d h 1 \Delta$, resp.), however, were able to grow on methanol as a sole source of carbon and energy, although the growth yields were only $10 \%$ and $25 \%$ of that observed for the wild-type strain, respectively $[33,34]$. These results suggested that although FGH and FDH are not essential, they contribute to optimal growth in the presence of methanol. We further showed that methyl formate synthesis catalyzed by cytosolic alcohol dehydrogenase $(\mathrm{ADH})$ contributed to formaldehyde detoxification through GSH-independent formaldehyde oxidation during growth on methanol [35].

\section{Roles and Function of Peroxisomes in Methanol Metabolism}

Oxidation of methanol in methylotrophic yeasts results in the formation of two very reactive and toxic compounds, formaldehyde and hydrogen peroxide. The enzymes involved in the metabolism of these compounds, namely AOD, DAS, CTA, and Pmp20, are compartmentalized in peroxisomes [16]. The presence of hydrogen peroxide-producing oxidases and catalase in a shared compartment is a characteristic feature of peroxisomes in all eukaryotes which offers the advantage of tightly linking production and breakdown of this toxic compound, preventing its diffusion into the cytosol [15]. The physiological roles of peroxisomal antioxidant enzymes and the antioxidative responses underlying yeast methylotrophy are described below (see Section 5).
Both AOD and DAS are major components of the peroxisomal matrix, suggesting that the generation and fixation of formaldehyde is primarily confined to this organelle. Compartmentalization of the formaldehyde conversion reactions in a membrane-bound organelle may be one cellular strategy to avoid formaldehyde toxicity. Furthermore, GSH was also shown to be present in the peroxisome at a physiologically significant level [36], indicating that S-HMG can be formed within peroxisomes and then exported to the cytosol $[32,33]$.

The peroxisomal localization of peroxisome matrix enzymes is essential for allowing methylotrophic yeasts to grow on methanol $[37,38]$. Intact peroxisomes are crucial to support growth of cells on methanol as a sole source of carbon and energy. The function of peroxisomes during methylotrophic growth is (i) to allow proper partitioning of formaldehyde generated from methanol via the assimilation and dissimilation pathways and (ii) to provide a site for scavenging hydrogen peroxide. These characteristics have been an important tool in the isolation of peroxisomedeficient mutants (pex) of methylotrophic yeast species, as such mutants lose the capacity to grow on methanol despite the fact that they have all the enzymes needed for methanol metabolism $[39,40]$. Detailed physiological studies of yeast pex mutants have revealed why compartmentalization is essential for methylotrophic growth [41]. Many PEX genes encoding peroxins, which are proteins involved in peroxisome biogenesis, peroxisomal matrix protein import, membrane biogenesis, peroxisome proliferation, and peroxisome inheritance, have been identified and later characterized using methylotrophic yeasts as model organisms [16].

\section{Regulation of Methanol-Inducible Gene Expression in Methylotrophic Yeast}

The key enzymes of methanol metabolism mentioned above are highly induced by methanol and are virtually absent in cells growing on glucose. We have studied the regulation of the expression of genes encoding these enzymes in cells grown on various carbon and nitrogen sources in C. boidinii. Furthermore, we have evaluated in detail the strength and regulation of the methanol-inducible promoters using a sensitive reporter system based on the acid phosphatase gene (PHO5) from Saccharomyces cerevisiae [42]. 


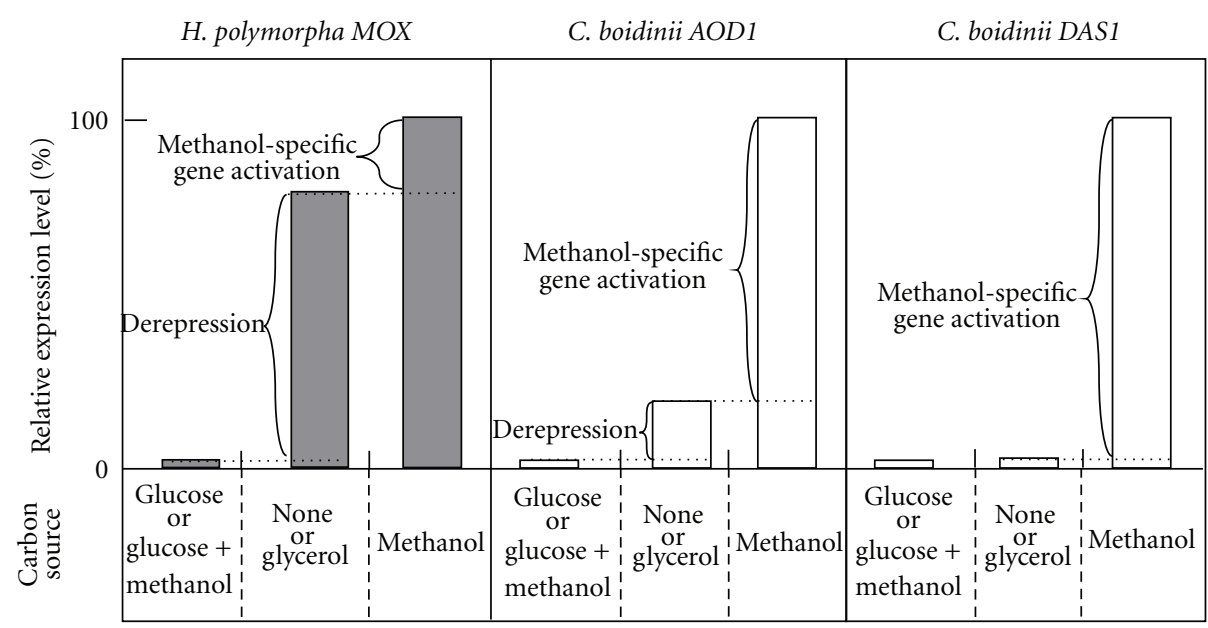

(a)

\begin{tabular}{|c|ccc|}
\hline $\begin{array}{c}\text { Carbon } \\
\text { source }\end{array}$ & Glucose $\longrightarrow$ Methanol \\
\hline $\begin{array}{c}\text { Regulation } \\
\text { status }\end{array}$ & $\begin{array}{c}\text { Glucose } \\
\text { repression }\end{array}$ & Derepression $\longrightarrow \begin{array}{c}\text { Methanol-specific } \\
\text { induction }\end{array}$ \\
\hline $\begin{array}{c}\text { Transcriptional level of } \\
\text { methanol-inducible } \\
\text { genes and } \\
\text { transcriptional factors }\end{array}$ & None $\longrightarrow$ Low & High \\
\hline
\end{tabular}

(b)

FIGURE 2: Molecular mechanism of methanol-inducible gene expression. (a) Relative expression levels of H. polymorpha MOX (encoding AOD), C. boidinii AOD1, and C. boidinii DAS1 during growth on various carbon sources. On glucose-containing media, expression is completely repressed. When glucose is completely consumed or cells are shifted to glycerol medium, a derepressed level of expression of the AOD genes is induced (derepression) and the extent of derepression of the AOD genes differs between H. polymorpha and C. boidinii. When cells are grown on methanol, the maximum level of expression of AOD genes is achieved not only by derepression but also by methanol-specific gene activation. The induction of DAS1 on methanol medium is achieved only by methanol-specific gene activation. (b) During growth on glucose, expression of methanol-inducible genes is repressed. When cells are shifted to methanol, initially, a Trm2prelated derepression event occurs followed by a Trm1p-related methanol-specific gene activation.

Maximal expression of the methanol-inducible genes is thought to be exerted through two modes of regulation, that is, derepression and methanol-specific gene activation $[14,22,29]$. The former refers to activation of genes in a manner independent of the availability of methanol, and the latter refers to activation of genes in response to methanol (Figure 2(a)). When grown on glycerol, $C$. boidinii and $H$. polymorpha exhibited $\sim 10$ and $80 \%$ of the methanol-induced maximum AOD expression level, respectively. Glucose-limited chemostat culture experiments also showed that the levels of AOD in $H$. polymorpha gradually increased with decreasing dilution, whereas the derepression of $\mathrm{AOD}$ was lower in C. boidinii than in $H$. polymorpha [44]. Therefore, the extent and mode of derepression differs among methylotrophic yeast species. In $C$. boidinii, the $A O D 1$ promoter was shown to have a maximum level of expression in cells grown on methanol, a derepressed level of expression in cells grown on glycerol or oleate, and was repressed in cells grown on glucose or ethanol (Figure 2(a)).
The DAS1 promoter did not appear to be derepressed when cells were grown on any of the alternative carbon sources [42], indicating that the derepressed level of expression of methanol-inducible genes is gene-specific even in $C$. boidinii. Based on these observations, we were able to determine a number of genetic factors specific to methanol induction in C. boidinii, particularly in regard to methanol-specific gene activation as opposed to derepression.

In H. polymorpha, Mpp1p regulates levels of peroxisomal matrix proteins and peroxins [45]. Further, the SWI/SNF complex (Swilp and Snf2p) in H. polymorpha plays a role in the transcriptional control of methanol-inducible gene expression, suggesting that chromatin remodeling participates in the transcriptional regulation of methanol-inducible genes [46]. In P. pastoris, Mxrlp (a homologue of the $\mathrm{C}_{2} \mathrm{H}_{2}$-type transcriptional factor Adr1p in S. cerevisiae) was shown to control transcription of genes involved in methanol metabolism, in particular $A O D 1$, as well as the $P E X$ genes [47]. All of these transcriptional regulators appear to be 


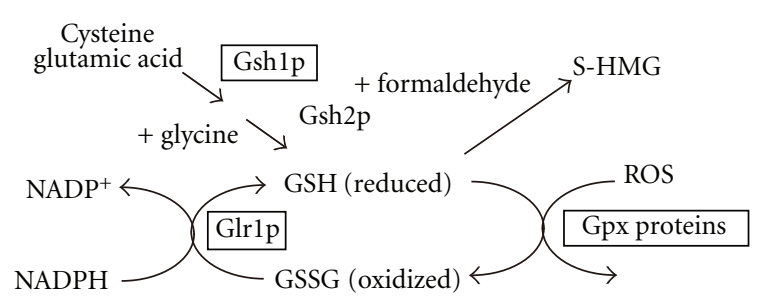

FIGURE 3: Schematic drawing of GSH dynamics and its regulation by Yap1. The proteins enclosed within the boxes represent factors found to be induced by Yap1 at the level of transcription. Enzymes: Gsh1p: $\gamma$-glutamylcysteine synthetase; Gsh2p: glutathione synthetase; Glr1p: glutathione reducatse; Gpx: glutathione peroxidase. S-HMG: S-hydroxymethyl glutathione; GSH: reduced form of glutathione; GSSG: oxidized form of glutathione; ROS: reactive oxygen species.

involved in glucose derepression of gene expression; however, we have also identified a novel gene, TRM1, as a putative regulator of methanol-specific gene activation [48].

Trm1p belongs to the $\mathrm{Zn}(\mathrm{II})_{2} \mathrm{Cys}_{6}$-type zinc cluster protein family, members of which are known to be transcriptional regulators in fungi [49]. Deletion of the TRM1 gene completely prevented growth on methanol, whereas it did not cause a defect in growth on glucose or other nonfermentative carbon sources, including glycerol, ethanol, or oleic acid. These results suggested that Trm1p is more involved in the regulation of methanol-specific gene activation than in derepression. The transcriptional activities of all of the methanol-inducible promoters tested drastically decreased in the trm1 $1 \Delta$ strain grown in methanol medium. Thus, Trm1p was shown to be a master transcriptional regulator of methanol-specific gene activation in the methylotrophic yeast $C$. boidinii.

With respect to derepression, we recently isolated and characterized $\operatorname{Trm} 2 \mathrm{p}$, which is homologous to P. pastoris Mxrlp and S. cerevisiae Adrlp [50]. A C. boidinii mutant $(\operatorname{trm} 2 \Delta)$ could not grow on methanol or oleate but could grow on glucose or ethanol. Trm $2 p$ was necessary for the activation of five methanol-inducible promoters tested. The derepressed level of expression of $A O D 1$, which was observed in the trm $1 \Delta$ strain, decreased in the $\operatorname{trm} 1 \Delta \operatorname{trm} 2 \Delta$ strain to a level similar to that observed in the $\operatorname{trm} 2 \Delta$ strain. These results suggest that $\operatorname{Trm} 2 \mathrm{p}$-dependent derepression is essential for Trmlp-dependent methanol-specific gene activation in C. boidinii (Figure 2(b)).

Recently, a transcriptome analysis of $H$. polymorpha cells shifted from glucose- to methanol-containing media was reported [51]. As expected, genes involved in methanol metabolism and several PEX genes were highly upregulated after 2 hours incubation on methanol. Among 1184 genes, which were significantly upregulated with at least a two-fold expression, highest upregulation ( $>300$-fold) was observed for the genes encoding a dissimilation pathway enzyme FDH and a transcriptional factor Mpp1. Autophagy-related genes (ATG genes; see Section 6) were also upregulated. In $P$. pastoris, autophagy was shown to be induced at the lag phase of the methylotrophic growth as described below [52].

\section{Antioxidative Responses Underlying Methylotrophy in Yeasts}

Because methanol metabolism in methylotrophic yeasts inevitably produces hydrogen peroxide, the organisms possess functions protective against oxidative stress, including induction of CTA and glutathione peroxidases. In C. boidinii, a CTA-deficient mutant (cta1 $\Delta$ ) was able to grow on methanol as a sole carbon source although its growth rate was much lower than that of the wild-type strain. The peroxisomal localization of CTA is essential for its function [43]. A $20-\mathrm{kDa}$ peroxisomal peripheral membrane protein of C. boidinii (Pmp20) was identified as peroxiredoxin, an enzyme with antioxidant activity necessary for methylotrophic growth [36]. Interestingly, the $p m p 20 \Delta$ strain had a more severe growth defect than the cta1 $\Delta$ strain. Pmp20 is localized to peroxisomes and has the ability to reduce alkyl hydroperoxide species, which suggests a role in elimination of other reactive oxygen species derived from hydrogen peroxide (Figure 1).

In order for the system that protects cells against oxidative stress to function properly, sufficient GSH is necessary to serve as a cosubstrate in the reaction mediated by glutathione peroxidases (Figure 3). GSH is also utilized to form $S$-HMG, a formaldehyde conjugate that serves as an intermediate metabolite in the catabolism of methanol. Thus, it is plausible that the amount of GSH available for catabolic and antioxidative pathways plays a vital role in yeast methylotrophy.

Upregulation of GSH is accomplished through induction of its de novo synthesis and regeneration. The synthesis pathway begins with the reaction catalyzed by Gsh $1 \mathrm{p}$ ( $\gamma$-glutamylcysteine synthetase) to form $\gamma$-glutamylcysteine. The second and last step catalyzed by Gsh2p (glutathione synthetase) conjugates L-glycine to $\gamma$-glutamylcysteine. Because the Gsh1p-mediated reaction is rate limiting, induction of Gsh1p expression plays a central role in upregulating GSH levels. The regeneration of free GSH from its oxidized form is catalyzed by Glrlp (glutathione reductase) at the expense of NADPH. In addition, the GSH pool is also partially replenished from its conjugate form $S$-HMG, via the activities of FLD and FGH. Thus, we anticipated that deciphering the molecular mechanisms governing induction of these enzymes would be important for elucidating redoxrelated regulatory mechanisms in methylotrophic yeasts.

A recent study demonstrated that a transcription factor termed Yap1 plays an important role in the upregulation of GSH-related enzymes in P. pastoris [53]. Disruption of $P p Y A P 1$ led to defects in transcriptional induction of genes encoding PpGlr1p, PpGshlp, and a glutathione peroxidase PpGpxlp and caused severe growth arrest in methanol culture. PpYap1p fused to a fluorescent tag was found to change localization from the cytoplasm to the nucleus several hours after the onset of methanol culture, validating the role of PpYap1 in the antioxidative response. Loss of genes required for GSH regeneration from S-HMG (PpFLD1 or PpFGH1) enhanced Yap1 translocation, which suggests an increased demand for GSH in these gene mutants. Of note, disruption of PpGLR1 caused a severe growth defect concomitantly 


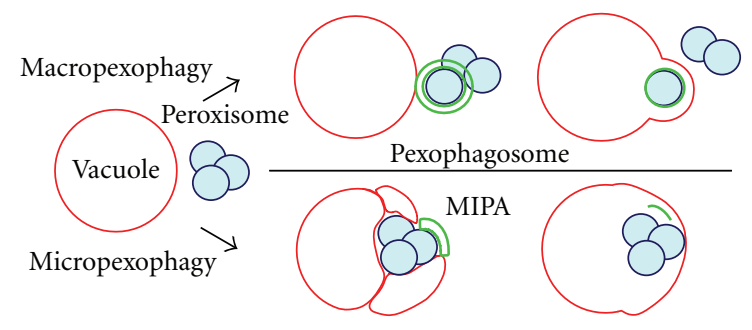

Figure 4: Model of organelle dynamics observed during pexophagy in methylotrophic yeasts. The green portions of the figure (MIPA and pexophagosome) represent autophagic membrane structures newly synthesized by the action of Atg proteins.

with abnormal accumulation of formaldehyde in methanol culture, showing that regeneration of GSH from its oxidized form plays a vital role in methylotrophy in this organism.

The molecular details of PpYaplp response were further investigated in another study [54]. PpYap1p has two cysteinerich domains (CRDs) similar to its homologue in S. cerevisiae. Each of the CRDs has two cysteine residues essential for induction of TRR1 (encoding thioredoxin reductase) in response to hydrogen peroxide treatment. This response was dependent on PpGpxlp, similar to the S. cerevisiae Yap1p response that requires ScGpx3p. These functional characteristics of PpYap1 are thought to underlie antioxidant activities in methanol culture.

\section{Autophagic Activities for Regulations of Methylotrophy}

As mentioned above, one remarkable feature of methylotrophy in eukaryotes is that many of the enzymes required for methanol metabolism are located in peroxisomes. This means that the regulation of methanol metabolism can be accomplished in part, through control of organelle homeostasis. Methylotrophic yeasts have been utilized as valuable experimental systems for elucidating molecular mechanisms of peroxisome biogenesis and degradation [55]. Studies in these yeasts in fact contributed to establishing terms now widely used for genes involved in peroxisome biogenesis, the so-called PEX genes, and autophagy-related genes $(A T G)$. Below, we briefly summarize what is known about the involvement of autophagy in regulating peroxisome homeostasis.

The term autophagy refers to the transport of cytoplasmic components to the lysosome/vacuole, followed by their degradation inside the lysosome/vacuole. Methylotrophic yeasts have peroxisome-selective autophagic machinery to reduce peroxisome quantity. This activity, termed pexophagy, is induced when nutrient conditions change from those requiring peroxisome function (e.g., growth in methanol culture) to those irrelevant to peroxisomal activities (e.g., growth in glucose or ethanol culture) $[56,57]$.

Pexophagy has been classified into two modes according to differences in organelle dynamics (Figure 4) [58]. In macropexophagy, the peroxisome is encapsulated within a newly synthesized double-membrane structure termed the pexophagosome. After sequestering the peroxisome from the cytoplasm, the pexophagosome fuses with the limiting membrane of the vacuole, resulting in release of its content and its inner membrane into the vacuole. In micropexophagy, a portion of the peroxisome surface is covered by a flat double-membrane structure termed the micropexophagy apparatus, or MIPA [59]. The remainder of the peroxisome surface is engulfed by extension of the vacuolar membrane, with fusion between the MIPA and the vacuolar membrane sealing the peroxisome within the vacuolar compartment. To date, micropexophagy has only been observed in P. pastoris.

Most proteins responsible for pexophagy are also needed for other autophagic pathways and are now considered Atg proteins, as noted above. This is because in many autophagic pathways, including the two modes of pexophagy, de novo synthesis of membrane structures plays a crucial role, requiring a shared molecular machinery for modulating membrane dynamics. Studies to elucidate the molecular mechanisms by which Atg proteins form membrane structures have been a major focus of research efforts [60].

A recent study demonstrated that autophagic activity also plays an important role in peroxisome biogenesis in methylotrophic yeast [52]. Autophagy was reported to be induced at lag phase following a shift from growth on glucose to methanol. This induction was observed only in minimal medium as addition of excess amino acids inhibits the induction. Loss of several $A T G$ genes led to a prolonged lag phase, indicating a physiological function of for autophagic activity during adaptation to growth on methanol. The carbon source shift forces cells to remodel metabolic systems and to increase the peroxisome quantity, which requires a substantial supply of amino acids. The induced autophagy (termed lag-phase autophagy) should have the effect of increasing amino acid pools through degradation of cellular components in the vacuole.

\section{Perspectives}

Heterologous gene expression systems using methylotrophic yeasts are based on the unique methanol metabolism of these organisms and are characterized by strong and tightly regulated methanol-inducible gene expression We anticipate that additional studies of the molecular basis for methylotrophy in yeasts that focus on transcriptional machinery and signal transduction pathways involved in methanol-inducible gene expression, and mechanisms that regulate organelle homeostasis and redox state will lead to improvements in these heterologous gene expression systems.

Methylotrophs play important roles in carbon recycling in natural environments. The symbiotic relationship between plants and methylotrophic bacteria has been the focus of recent intensive study [61-63]. In contrast, the relationship between plants and methylotrophic yeasts has not been extensively characterized, although methylotrophic yeasts have often been isolated from plant-related materials $[5,16]$. We previously reported that $C$. boidinii can grow on pectin and that this ability depends on methylotrophy [26]. Further intensive analysis of the molecular basis of 
yeast methylotrophy is expected to reveal new physiological functions and their importance in natural environments.

\section{Acknowledgments}

This paper was supported in part by CREST, JST and by the Ministry of Education, Culture, Sports, Science, and Technology of Japan.

\section{References}

[1] C. Anthony, The Biochemistry of Methylotrophs, Academic Press, London, UK, 1982.

[2] H. Yurimoto, N. Kato, and Y. Sakai, "Assimilation, dissimilation, and detoxification of formaldehyde, a central metabolic intermediate of methylotrophic metabolism," Chemical Record, vol. 5, no. 6, pp. 367-375, 2005.

[3] L. Chistoserdova, M. G. Kalyuzhnaya, and M. E. Lidstrom, "The expanding world of methylotrophic metabolism," Annual Review of Microbiology, vol. 63, pp. 477-499, 2009.

[4] L. Chistoserdova, "Modularity of methylotrophy, revisited," Environmental Microbiology. In press.

[5] S. Limtong, N. Srisuk, W. Yongmanitchai, H. Yurimoto, and T. Nakase, "Ogataea chonburiensis sp. nov. and Ogataea nakhonphanomensis sp. nov., thermotolerant, methylotrophic yeast species isolated in Thailand, and transfer of Pichia siamensis and Pichia thermomethanolica to the genus Ogataea," International Journal of Systematic and Evolutionary Microbiology, vol. 58, no. 1, pp. 302-307, 2008.

[6] K. Ogata, H. Nishikawa, and M. Ohsugi, "A yeast capable of utilizing methanol," Agricultural and Biological Chemistry, vol. 33, no. 10, pp. 1519-1520, 1969.

[7] P. J. Senior and J. Windass, "The ICI single cell protein process," Biotechnology Letters, vol. 2, no. 5, pp. 205-210, 1980.

[8] J. H. Litchfield, "Single-cell proteins," Science, vol. 219, no. 4585, pp. 740-746, 1983.

[9] M. Veenhuis, J. P.V. Dijken, and W. Harder, "The significance of peroxisomes in the metabolism of one-carbon compounds in yeasts," Advances in Microbial Physiology, vol. 24, pp. 1-82, 1983.

[10] Y. Tani, "Microbiology and biochemistry of methylotrophic yeasts," in Methylotrophs: Microbiology, Biochemistry, and Genetics, C. T. Hou, Ed., pp. 55-86, CRC Press, Boca Raton, Fla, USA, 1984.

[11] P. J. Large and C. W. Bamforth, Methylotrophy and Biotechnology, Longman Scientific \& Technical, Harlow, UK, 1988.

[12] J. C. Murrell and H. Dalton, Methane and Methanol Utilizers, Plenum Press, New York, NY, USA, 1992.

[13] H. Yurimoto, Y. Sakai, and N. Kato, "Methanol metabolism," in Hansenula Polymorpha-Biology and Applications, G. Gellissen, Ed., pp. 61-75, Wiley-VCH, Weinheim, Germany, 2002.

[14] F. S. Hartner and A. Glieder, "Regulation of methanol utilisation pathway genes in yeasts," Microbial Cell Factories, vol. 5, article 39, 2006.

[15] P. E. Purdue and P. B. Lazarow, "Peroxisome biogenesis," Annual Review of Cell and Developmental Biology, vol. 17, pp. 701-752, 2001.

[16] I. J. van der Klei, H. Yurimoto, Y. Sakai, and M. Veenhuis, "The significance of peroxisomes in methanol metabolism in methylotrophic yeast," Biochimica et Biophysica Acta, vol. 1763, no. 12, pp. 1453-1462, 2006.
[17] Y. Sakai, M. Oku, I. J. van der Klei, and J. A. K. W. Kiel, "Pexophagy: autophagic degradation of peroxisomes," Biochimica et Biophysica Acta, vol. 1763, no. 12, pp. 1767-1775, 2006.

[18] J. M. Cregg, J. L. Cereghino, J. Shi, and D. R. Higgins, "Recombinant protein expression in Pichia pastoris," Applied Biochemistry and Biotechnology. Part B, vol. 16, no. 1, pp. 23$52,2000$.

[19] G. Gellissen, "Heterologous protein production in methylotrophic yeasts," Applied Microbiology and Biotechnology, vol. 54, no. 6, pp. 741-750, 2000.

[20] C. K. Raymond, T. Bukowski, S. D. Holderman, A. F.T. Ching, E. Vanaja, and M. R. Stamm, "Development of the methylotrophic yeast Pichia methanolica for the expression of the 65 kilodalton isoform of human glutamate decarboxylase," Yeast, vol. 14, no. 1, pp. 11-23, 1998.

[21] Y. Sakai, Y. Tani, and N. Kato, "Biotechnological application of cellular functions of the methylotrophic yeast," Journal of Molecular Catalysis B, vol. 6, no. 3, pp. 161-173, 1999.

[22] H. Yurimoto and Y. Sakai, "Methanol-inducible gene expression and heterologous protein production in the methylotrophic yeast Candida boidinii," Biotechnology and Applied Biochemistry, vol. 53, no. 2, pp. 85-92, 2009.

[23] G. A. Olah, "Beyond oil and gas: the methanol economy," Angewandte Chemie. International Edition, vol. 44, no. 18, pp. 2636-2639, 2005.

[24] G. A. Olah, A. Goeppert, and G. K. S. Prakash, Beyond Oil and Gas: The Methanol Economy, Wiley-VCH, Weinheim, Germany, 2006.

[25] T. Chmielniak and M. Sciazko, "Co-gasification of biomass and coal for methanol synthesis," Applied Energy, vol. 74, no. 3-4, pp. 393-403, 2003.

[26] T. Nakagawa, T. Miyaji, H. Yurimoto, Y. Sakai, N. Kato, and N. Tomizuka, "A methylotrophic pathway participates in pectin utilization by Candida boidinii," Applied and Environmental Microbiology, vol. 66, no. 10, pp. 4253-4257, 2000.

[27] R. Mitsui, Y. Kusano, H. Yurimoto, Y. Sakai, N. Kato, and M. Tanaka, "Formaldehyde fixation contributes to detoxification for growth of a nonmethylotroph, Burkholderia cepacia TM1, on vanillic acid," Applied and Environmental Microbiology, vol. 69, no. 10, pp. 6128-6132, 2003.

[30] T. Nakagawa, H. Mukaiyama, H. Yurimoto, Y. Sakai, and N. Kato, "Alcohol oxidase hybrid oligomers formed in vivo and in vitro," Yeast, vol. 15, no. 12, pp. 1223-1230, 1999.

[31] Y. Sakai, T. Nakagawa, M. Shimase, and N. Kato, "Regulation and physiological role of the DAS1 gene, encoding dihydroxyacetone synthase, in the methylotrophic yeast Candida boidinii," Journal of Bacteriology, vol. 180, no. 22, pp. 58855890, 1998.

[32] B. Lee, H. Yurimoto, Y. Sakai, and N. Kato, "Physiological role of the glutathione-dependent formaldehyde dehydrogenase in the methylotrophic yeast Candida boidinii," Microbiology, vol. 148, no. 9, pp. 2697-2704, 2002.

[33] H. Yurimoto, B. Lee, T. Yano, Y. Sakai, and N. Kato, "Physiological role of $S$-formylglutathione hydrolase in C metabolism of the methylotrophic yeast Candida boidinii," Microbiology, vol. 149, no. 8, pp. 1971-1979, 2003.

[34] Y. Sakai, A. P. Murdanoto, T. Konishi, A. Iwamatsu, and N. Kato, "Regulation of the formate dehydrogenase gene, FDH1, in the methylotrophic yeast Candida boidinii and growth characteristics of an FDH1-disrupted strain on methanol, methylamine, and choline," Journal of Bacteriology, vol. 179, no. 14 , pp. 4480-4485, 1997. 
[35] H. Yurimoto, B. Lee, F. Yasuda, Y. Sakai, and N. Kato, "Alcohol dehydrogenases that catalyse methyl formate synthesis participate in formaldehyde detoxification in the methylotrophic yeast Candida boidinii," Yeast, vol. 21, no. 4, pp. 341-350, 2004.

[43] H. Horiguchi, H. Yurimoto, T. K. Goh, T. Nakagawa, N. Kato, and Y. Sakai, "Peroxisomal catalase in the methylotrophic yeast Candida boidinii: transport efficiency and metabolic significance," Journal of Bacteriology, vol. 183, no. 21, pp. 6372-6383, 2001.

[36] H. Horiguchi, H. Yurimoto, N. Kato, and Y. Sakai, "Antioxidant system within yeast peroxisome. Biochemical and physiological characterization of CbPmp20 in the methylotrophic yeast Candida boidinii," Journal of Biological Chemistry, vol. 276, no. 17, pp. 14279-14288, 2001.

[28] N. Harms, J. Ras, W. N. M. Reijnders, R. J. M. Van Spanning, and A. H. Stouthamer, " $S$-formylglutathione hydrolase of Paracoccus denitrificans is homologous to human esterase D: a universal pathway for formaldehyde detoxification?" Journal of Bacteriology, vol. 178, no. 21, pp. 6296-6299, 1996.

[29] H. Yurimoto, "Molecular basis of methanol-inducible gene expression and its application in the methylotrophic yeast Candida boidinii," Bioscience, Biotechnology and Biochemistry, vol. 73, no. 4, pp. 793-800, 2009.

[37] M. Veenhuis and W. Harder, "Microbodies in yeasts: structure, function and biogenesis," Microbiological sciences, vol. 5, no. 11, pp. 347-351, 1988.

[38] M. Veenhuis, F. A. Salomons, and I. J. Van Der Klei, "Peroxisome biogenesis and degradation in yeast: a structure/function analysis," Microscopy Research and Technique, vol. 51, no. 6, pp. 584-600, 2000.

[39] J. M. Cregg, I. J. van der Klei, G. J. Sulter, M. Veenhuis, and W. Harder, "Peroxisome-deficient mutants of Hansenula polymorpha," Yeast, vol. 6, no. 2, pp. 87-97, 1990.

[40] H. Liu, X. Tan, M. Veenhuis, D. McCollum, and J. M. Cregg, "An efficient screen for peroxisome-deficient mutants of Pichia pastoris," Journal of Bacteriology, vol. 174, no. 15, pp. 49434951, 1992.

[41] I. J. Van der Klei, W. Harder, and M. Veenhuis, "Methanol metabolism in a peroxisome-deficient mutant of Hansenula polymorpha: a physiological study," Archives of Microbiology, vol. 156, no. 1, pp. 15-23, 1991.

[42] H. Yurimoto, T. Komeda, C. R. Lim et al., "Regulation and evaluation of five methanol-inducible promoters in the methylotrophic yeast Candida boidinii," Biochimica et Biophysica Acta, vol. 1493, no. 1-2, pp. 56-63, 2000.

[44] T. Egli, J. P. van Dijken, M. Veenhuis, W. Harder, and A. Fiechter, "Methanol metabolism in yeasts: regulation of the synthesis of catabolic enzymes," Archives of Microbiology, vol. 124, no. 2-3, pp. 115-121, 1980.

[45] A. N. Leão-Helder, A. M. Krikken, I. J. Van der Klei, J. A. K. W. Kiel, and M. Veenhuis, "Transcriptional down-regulation of peroxisome numbers affects selective peroxisome degradation in Hansenula polymorpha," Journal of Biological Chemistry, vol. 278, no. 42, pp. 40749-40756, 2003.

[46] P. Ozimek, K. Lahtchev, J. A. K. W. Kiel, M. Veenhuis, and I. J. Van Der Klei, "Hansenula polymorpha Swilp and Snf2p are essential for methanol utilisation," FEMS Yeast Research, vol. 4, no. 7, pp. 673-682, 2004.

[47] G. P. Lin-Cereghino, L. Godfrey, B. J. De La Cruz et al., "Mxr1, a key regulator of the methanol utilization pathway and peroxisomal genes in Pichia pastoris," Molecular and Cellular Biology, vol. 26, no. 3, pp. 883-897, 2006.

[48] YU. Sasano, H. Yurimoto, M. Yanaka, and Y. Sakai, "Trm1p, a $\mathrm{Zn}(\mathrm{II})_{2} \mathrm{Cys}_{6}$-type transcription factor, is a master regulator of methanol-specific gene activation in the methylotrophic yeast Candida boidinii," Eukaryotic Cell, vol. 7, no. 3, pp. 527-536, 2008.

[49] S. MacPherson, M. Larochelle, and B. Turcotte, "A fungal family of transcriptional regulators: the zinc cluster proteins," Microbiology and Molecular Biology Reviews, vol. 70, no. 3, pp. 583-604, 2006.

[50] Y. Sasano, H. Yurimoto, M. Kuriyama, and Y. Sakai, “Trm2pdependent derepression is essential for methanol-specific gene activation in the methylotrophic yeast Candida boidinii," FEMS Yeast Research, vol. 10, no. 5, pp. 535-544, 2010.

[51] T. van Zutphen, R. J. S. Baerends, K. A. Susanna et al., "Adaptation of Hansenula polymorpha to methanol: a transcriptome analysis," BMC Genomics, vol. 11, no. 1, article no. 1, 2010.

[52] S. I. Yamashita, H. Yurimoto, D. Murakami, M. Yoshikawa, M. Oku, and Y. Sakai, "Lag-phase autophagy in the methylotrophic yeast Pichia pastoris," Genes to Cells, vol. 14, no. 7, pp. 861-870, 2009.

[53] T. Yano, E. Takigami, H. Yurimoto, and Y. Sakai, "Yap1regulated glutathione redox system curtails accumulation of formaldehyde and reactive oxygen species in methanol metabolism of Pichia pastoris," Eukaryotic Cell, vol. 8, no. 4, pp. 540-549, 2009.

[54] T. Yano, H. Yurimoto, and Y. Sakai, "Activation of the oxidative stress regulator PpYap1 through conserved cysteine residues during methanol metabolism in the yeast Pichia pastoris," Bioscience, Biotechnology and Biochemistry, vol. 73, no. 6, pp. 1404-1411, 2009.

[55] Y. Sakai and S. Subramani, "Environmental response of yeast peroxisomes. Aspects of organelle assembly and degradation," Cell Biochemistry and Biophysics, vol. 32, pp. 51-61, 2000.

[56] W. A. Dunn Jr., J. M. Cregg, J. A. Kiel et al., "Pexophagy: the selective autophagy of peroxisomes," Autophagy, vol. 1, no. 2, pp. 75-83, 2005.

[57] M. Oku and Y. Sakai, "Peroxisomes as dynamic organelles: autophagic degradation," FEBS Journal, vol. 277, no. 16, pp. 3289-3294, 2010.

[58] D. L. Tuttle and W. A. Dunn Jr., "Divergent modes of autophagy in the methylotrophic yeast Pichia pastoris," Journal of Cell Science, vol. 108, no. 1, pp. 25-35, 1995.

[59] H. Mukaiyama, M. Baba, M. Osumi et al., "Modification of a ubiquitin-like protein Paz2 conducted micropexophagy through formation of a novel membrane structure," Molecular Biology of the Cell, vol. 15, no. 1, pp. 58-70, 2004.

[60] Z. Xie and D. J. Klionsky, "Autophagosome formation: core machinery and adaptations," Nature Cell Biology, vol. 9, no. 10, pp. 1102-1109, 2007.

[61] Z. S. Omer, R. Tombolini, and B. Gerhardson, "Plant colonization by pink-pigmented facultative methylotrophic bacteria (PPFMs)," FEMS Microbiology Ecology, vol. 47, no. 3, pp. 319326, 2004.

[62] A. Sy, A. C. J. Timmers, C. Knief, and J. A. Vorholt, "Methylotrophic metabolism is advantageous for Methylobacterium extorquens during colonization of Medicago truncatula under competitive conditions," Applied and Environmental Microbiology, vol. 71, no. 11, pp. 7245-7252, 2005.

[63] C. Knief, L. Frances, F. Cantet, and J. A. Vorholt, "Cultivationindependent characterization of Methylobacterium populations in the plant phyllosphere by automated ribosomal intergenic spacer analysis," Applied and Environmental Microbiology, vol. 74, no. 7, pp. 2218-2228, 2008. 

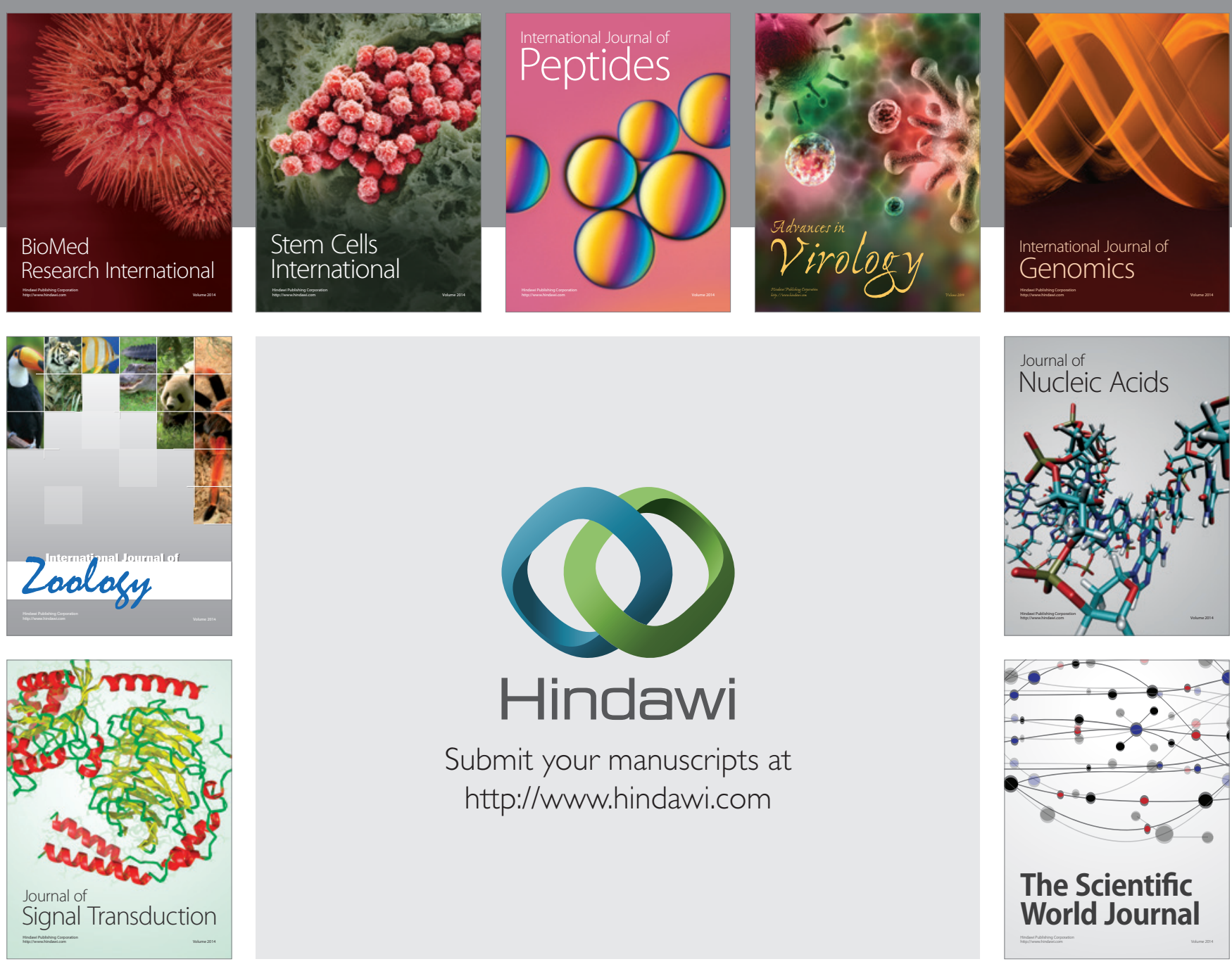

Submit your manuscripts at

http://www.hindawi.com
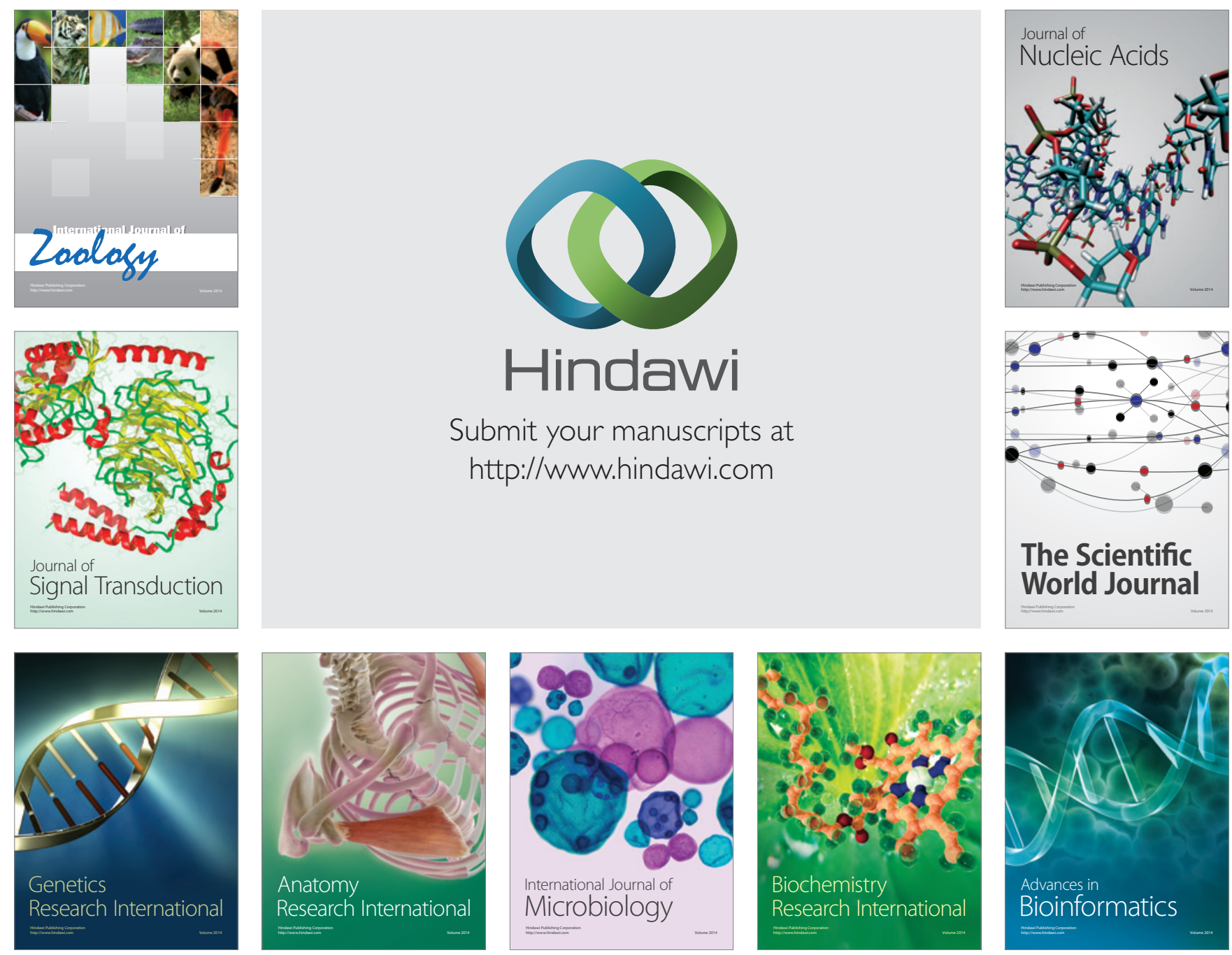

The Scientific World Journal
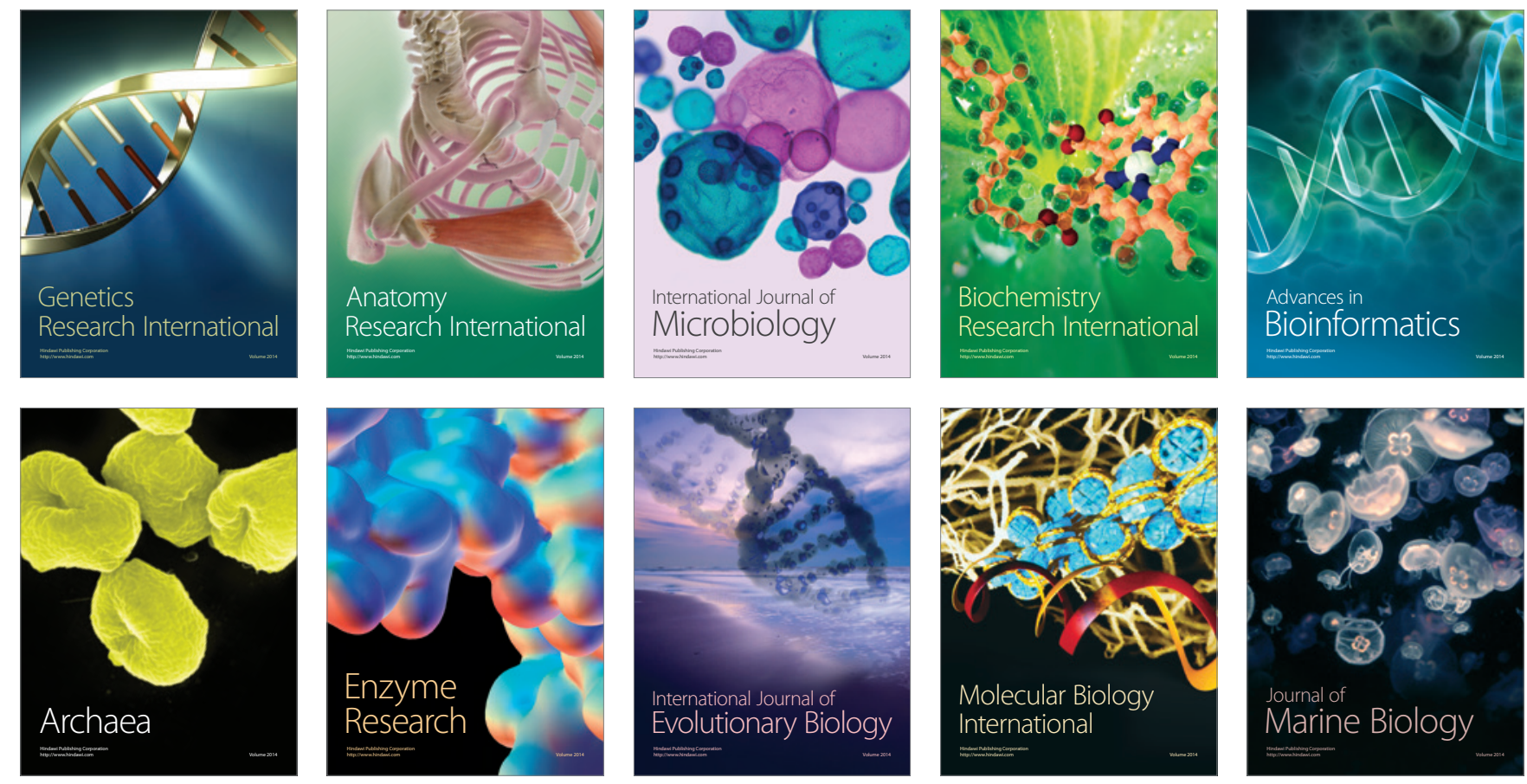